\title{
Biobjective Optimization and Evaluation for Transit Signal Priority Strategies at Bus Stop-to-Stop Segment
}

\author{
Rui Li, ${ }^{1}$ Peter J. Jin, ${ }^{2}$ and Bin $\operatorname{Ran}^{3}$ \\ ${ }^{1}$ College of Civil and Transportation Engineering, Hohai University, Xi Kang Road 1, Nanjing 210098, China \\ ${ }^{2}$ Department of Civil and Environmental Engineering, Rutgers, The State University of New Jersey, CoRE 613, 96 Frelinghuysen Road, \\ Piscataway, NJ 08854-8018, USA \\ ${ }^{3}$ School of Transportation, Southeast University, Si Pai Lou 2, Nanjing 210096, China
}

Correspondence should be addressed to Rui Li; lirui2012@hhu.edu.cn

Received 7 January 2016; Revised 23 April 2016; Accepted 26 April 2016

Academic Editor: M. I. Herreros

Copyright @ 2016 Rui Li et al. This is an open access article distributed under the Creative Commons Attribution License, which permits unrestricted use, distribution, and reproduction in any medium, provided the original work is properly cited.

\begin{abstract}
This paper proposes a new optimization framework for the transit signal priority strategies in terms of green extension, red truncation, and phase insertion at the stop-to-stop segment of bus lines. The optimization objective is to minimize both passenger delay and the deviation from bus schedule simultaneously. The objective functions are defined with respect to the segment between bus stops, which can include the adjacent signalized intersections and downstream bus stops. The transit priority signal timing is optimized by using a biobjective optimization framework considering both the total delay at a segment and the delay deviation from the arrival schedules at bus stops. The proposed framework is evaluated using a VISSIM model calibrated with field traffic volume and traffic signal data of Caochangmen Boulevard in Nanjing, China. The optimized TSP-based phasing plans result in the reduced delay and improved reliability, compared with the non-TSP scenario under the different traffic flow conditions in the morning peak hour. The evaluation results indicate the promising performance of the proposed optimization framework in reducing the passenger delay and improving the bus schedule adherence for the urban transit system.
\end{abstract}

\section{Introduction}

Traffic congestion has been a challenging problem in urban areas. Public transportation, with high passenger capacity per vehicle, has long been considered an effective solution for congestion mitigation. However, on urban arterials, the performance of public transportation such as bus transit is largely affected by the signal timing at intersections and the interaction between transit and other general vehicles. The transit signal priority (TSP) control has been found to be a promising and cost-effective solution to improve the efficiency and level of service. Smith was among the first to conduct bus preemption experiments to reduce transit travel time [1]. Since then, many studies have proposed different TSP scenarios and reported benefits in the field.

In existing studies, intersection-based state variables are used in transit signal priority control with isolated intersections $[2,3]$, coordinated intersections within an arterial corridor $[4,5]$, and arterial networks [6, 7]. Recently, TSP optimization strategies considering bus stop based performance metrics are paid more and more attentions. Ma et al. presented a coordinated transit priority control optimization model to provide effective priority control for transit while minimizing the adverse impact on general traffic movements among coordinated intersections between two successive bus stops [8]. Feng analyzed the joint effects of different kinds of factors and improvement strategies on bus traveling reliability at the stop-to-stop segment level using the data along an urban arterial corridor in Portland, Oregon, USA [9]. Traffic delay is chosen as an important variable in objective functions for TSP optimization. Such delay terms include transit vehicle delay [10], general vehicle delay [11], and passenger average delay [12]. A number of studies also utilized transit reliability as the other key evaluation parameter for TSP optimization. Existing studies use transit reliability indexes used in TSP optimization including traveling punctuality (transit schedule adherence) [13] and regularity (headway maintenance) [14]. Furthermore, the impacts of traffic flow characteristics 


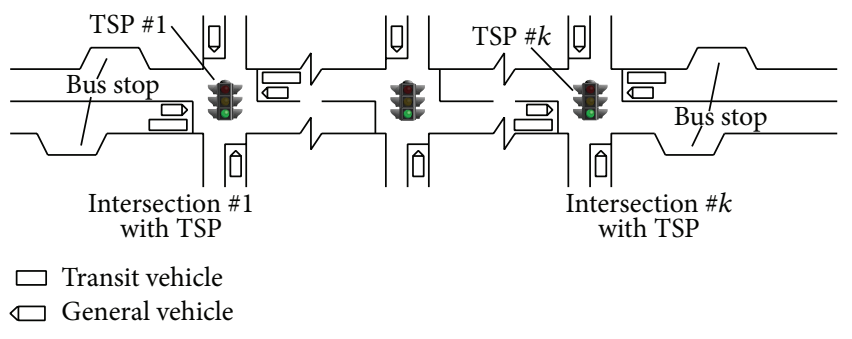

FIgURE 1: Visualization of the stop-to-stop segment.

[15], geometry configurations [16, 17], and lane-changing behaviors [18] have also been used in the objective function in TSP optimization. The methodologies for solving TSP optimization models include simulation-based methods [19], genetic algorithms [6,20], artificial neural network [20], heuristic algorithms [21], and multiobjective optimization [22]. The performance of different TSP strategies is analyzed and evaluated [4,23-25]. The analyzing unit in existing studies is primarily the stop-to-stop segment consisting of segment and intersection between two bus stops. Such analyzing scheme may ignore the interaction between bus stops and nearby upstream and downstream intersections [7]. Moreover, to evaluate the performance of transit systems, the excessive delay and poor schedule adherence should also be integrated into the objective functions.

The proposed TSP optimization model in this paper is a biobjective model considering both the traffic delay and transit service reliability. A VISSIM-based simulation platform is established for analyzing and evaluating the performance of three optimized TSP scenarios including the green extension, red truncation, and phase insertion. The simulation is calibrated by field traffic flow, signal, and transit schedule data on Caochangmen Boulevard in Nanjing, China.

The paper is organized as follows. In Section 2, the biobjective optimization framework is proposed including the analyzing unit, the formulation of objective functions, and the applied TSP scenarios. Section 3 is the field-data based analysis and evaluation of the proposed optimization framework and strategies. The three optimal TSP plans are generated, and the performance of them is analyzed and simulated by use of VISSIM-based simulation platform. Conclusions and recommendations are made in the last section.

\section{Methodology}

The proposed biobjective optimization framework is formulated with respect to the stop-to-stop segment as depicted in Figure 1. Such segment includes the road segment between two consecutive bus stops and the adjacent signalized intersections in between.

Such choice of the basic analyzing unit allows the simultaneous monitoring of both intersection-based and segmentbased performance metrics. Two performance metrics are introduced into the objective function of the optimization model, passenger delay, and transit schedule adherence. Passenger delay is a more suitable delay metric than vehicle delay since it takes into account the occupancy difference between auto and transit mode. The total passenger delay in the stop-to-stop segment including passenger delay at intersection and bus stop is considered for TSP optimization. Transit schedule adherence defined as arriving early or late from the scheduled stop arrival time is used as an indicator for the deterioration of system reliability. Three different TSP signal phasing plans are considered including the green extension, red truncation, and phase insertion.

2.1. Biobjective Optimization Model. The proposed biobjective optimization framework is described in (1). Both total passenger delay $(D)$ of the stop-to-stop segment and delay deviation $\left(\Delta d_{s}\right)$ of the bus service stop are in the objective functions for TSP optimization:

$$
\begin{array}{ll}
\min & D=\left(\sum_{k \in K} D_{I}(G, P)+\sum_{m \in M} \sum_{n \in N} d_{s}^{m n}(G, P)\right) \\
\min & \Delta d_{s}=\sum_{m \in M} \sum_{n \in N}\left|d_{s}^{m n}(G, P)-\widehat{d}_{s}^{m n}(G, P)\right| \\
\text { s.t. } & \max \frac{x_{i j k}}{\lambda_{i j k}} \leq 0.9 \quad i \in I, \quad j \in J, k \in K .
\end{array}
$$

$D_{I}(G, P)$ denotes the total passenger delay at the intersections on each stop-to-stop segment given the assigned green times $(G)$ and signal phasing plans $(P)$. In this paper, the duration of TSP green times and signal phasing plans are optimized with fixed cycle lengths. $K$ is the set of all intersections on the stop-to-stop segment. $M$ is the set of all transit routes on the segment. $N$ is the set of all buses on one transit route. $d_{s}^{m n}$ and $\widehat{d}_{s}^{m n}$ are the actual and scheduled passenger delays for bus $n$ of route $m$ at bus service stop. $\lambda_{i j k}$ and $x_{i j k}$ are the green time ratio and degree of saturation of general vehicles, respectively, for phase $j$ of cycle $i$ at intersection $k$.

2.1.1. Passenger Delay at Intersection. The total passenger delay at intersections on the stop-to-stop segment consists of the general vehicle delay, transit vehicle delay, pedestrian delay, and bicycle delay.

(1) General Vehicle Delay. Based on the Webster's delay formula, the average delay for general vehicles in phase $j$ of cycle $i$ at one signalized intersection is illustrated in

$$
\bar{d}_{g}^{i j}=\frac{C\left(1-\lambda_{g}^{i j}\right)^{2}}{2\left(1-\lambda_{g}^{i j} x_{g}^{i j}\right)}+\frac{x_{g}^{i j^{2}}}{2 q_{g}^{i j}\left(1-x_{g}^{i j}\right)},
$$

where $C$ is the cycle length and $\bar{d}_{g}^{i j}, q_{g}^{i j}, \lambda_{g}^{i j}$, and $x_{g}^{i j}$ are the average delay, arrival rate, green time ratio, and degree of saturation of general vehicles for phase $j$ of cycle $i$ at one intersection, respectively.

The formula for the total general vehicle delay at one intersection is addressed as the following:

$$
d_{g}=\sum_{i \in I} \sum_{j \in J}\left(\bar{d}_{g}^{i j} \times q_{g}^{i j} \times P_{g}^{i j}\right)
$$




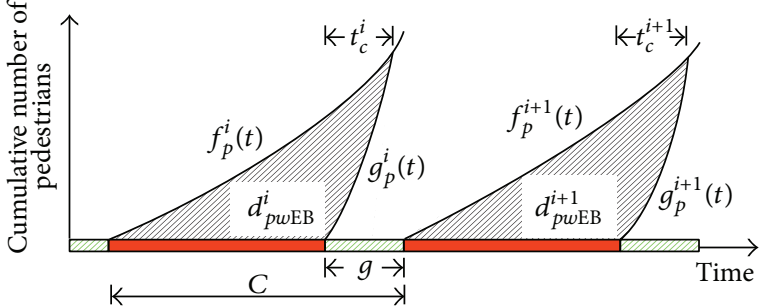

FIgURE 2: Illustrative pedestrian delay patterns at intersection.

where $I$ denotes the set of all cycles at one intersection during time $T, J$ denotes the set of all phases of a cycle at one intersection, and $P_{g}^{i j}$ is the average passenger occupancy of general vehicle for phase $j$ of cycle $i$ at one intersection.

(2) Transit Vehicle Delay. The average delay of transit vehicles in cycle $i$ at one signalized intersection can be formulated as follows:

$$
\bar{d}_{t}^{i}=\frac{C\left(1-\lambda_{t}^{i}\right)^{2}}{2\left(1-\lambda_{t}^{i} x_{t}^{i}\right)}+\frac{x_{t}^{i^{2}}}{2 q_{t}^{i}\left(1-x_{t}^{i}\right)},
$$

where $\bar{d}_{t}^{i}, q_{t}^{i}, \lambda_{t}^{i}$, and $x_{t}^{i}$ are the average delay, arrival rate, green time ratio, and degree of saturation of transit vehicles in cycle $i$ at one intersection, respectively. The passenger delay of transit vehicles at one intersection can be calculated as the following:

$$
d_{t}=\sum_{i \in I}\left(\bar{d}_{t}^{i} \times q_{t}^{i} \times P_{t}^{i}\right)
$$

where $P_{t}^{i}$ denotes the average passenger occupancy of buses in cycle $i$ at one intersection.

(3) Pedestrian Delay. Figure 2 illustrates the cycle-by-cycle accumulative flow patterns of pedestrians passing through one approach of the signalized intersection. The arrival and the average departure rate of pedestrians within each signal cycle $i$ are denoted by $f_{p}^{i}(t)$ and $g_{p}^{i}(t)$, respectively. Shaded areas $\left(d_{p w \mathrm{~EB}}^{i}\right)$ bounded by the arrival rate curve, departure rate curve, and the time axis are the total pedestrian delay on the eastbound approach of signalized intersection in cycle $i$. The passenger delay formula can then be described as follows:

$$
\begin{aligned}
d_{p w \mathrm{~EB}}^{i}= & \int_{0}^{C-g+t_{c}}\left(C-g+t_{c}-t\right) f_{p}^{i}(t) d t \\
& -\int_{0}^{t_{c}}\left(t_{c}-t\right) g_{p}^{i}(t) d t,
\end{aligned}
$$

where $g$ and $t_{c}$ denote, respectively, the green time and the clearance time for pedestrian to walk through the intersection. The pedestrian clearance time in each cycle can be generated based on

$$
f_{p}^{i}\left(C-g+t_{c}\right)=g_{p}^{i}\left(t_{c}\right)
$$

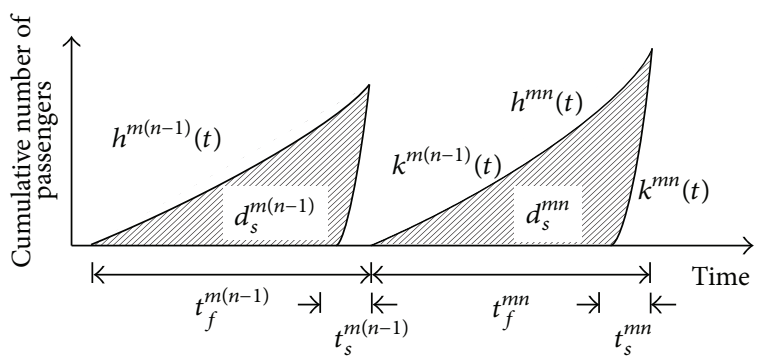

FIGURE 3: Illustrative passenger arrival and boarding patterns at bus stop.

The total pedestrian delay at a signalized intersection per cycle is calculated as below:

$$
d_{p w}=\sum_{i \in I}\left(d_{p w \mathrm{~EB}}^{i}+d_{p w \mathrm{SB}}^{i}+d_{p w \mathrm{NB}}^{i}+d_{p w \mathrm{WB}}^{i}\right)
$$

where $d_{p w \mathrm{SB}}^{i}, d_{p w \mathrm{NB}}^{i}$, and $d_{p w \mathrm{WB}}^{i}$ are the pedestrian delay on the southbound, northbound, and westbound approach of a signalized intersection in cycle $i$, respectively.

(4) Bicycle Delay. For most signalized intersections, bicycles usually utilize pedestrian green time to pass the intersection due to the lack of dedicated signal phase for bicycles. Therefore, the bicycle delay on the approach of signalized intersection in cycle $i$ (revealed in (9)) can be calculated based on the same model. The total delay of bicycles $\left(d_{b w}\right)$ at a signalized intersection within each cycle can be calculated using (10):

$$
\begin{aligned}
d_{b w \mathrm{~EB}}^{i}= & \int_{0}^{C-g+t_{c}}\left(C-g+t_{c}-t\right) f_{b}^{i}(t) d t \\
& -\int_{0}^{t_{c}}\left(t_{c}-t\right) g_{b}^{i}(t) d t, \\
d_{b w}= & \sum_{i \in I}\left(d_{b w \mathrm{SB}}^{i}+d_{b w \mathrm{NB}}^{i}+d_{b w \mathrm{~EB}}^{i}+d_{b w \mathrm{WB}}^{i}\right),
\end{aligned}
$$

where $d_{b w \mathrm{SB}}^{i}, d_{b w \mathrm{NB}}^{i}, d_{b w \mathrm{~EB}}^{i}$, and $d_{b w \mathrm{WB}}^{i}$ are the bicycle delays on $\mathrm{SB}, \mathrm{NB}, \mathrm{EB}$, and $\mathrm{WB}$ approaches of a signalized intersection, respectively. The arrival rate and departure rate of bicycles at an intersection in cycle $i$ are indicated by $f_{b}^{i}(t)$ and $g_{b}^{i}(t)$, respectively.

2.1.2. Passenger Delay at Bus Stop. Figure 3 illustrates the waiting delay patterns of passengers at bus stop bay with each bus arrival. The arrival and boarding rate of passengers bus $n$ of route $m$ at bus stop are $h^{m n}(t)$ and $k^{m n}(t)$, respectively.

The cross-point of $h^{m n}(t)$ and $k^{m n}(t)$ demonstrates the rate of passenger boarding the bus $n$ on route $m$. $t_{f}^{m n}$ denotes the headway between bus $n$ and $(n-1)$ on route $m$. The dwelling time of bus $n$ at the bus stop on route $m\left(t_{s}^{m n}\right)$ can be calculated as below:

$$
h^{m n}\left(t_{f}^{m n}\right)=k^{m n}\left(t_{s}^{m n}\right) .
$$

The shaded area $\left(d_{s}^{m n}\right)$ surrounded by $h^{m n}(t)$ and $k^{m n}(t)$ curves and the time axis is the passenger delay for bus $n$ of 


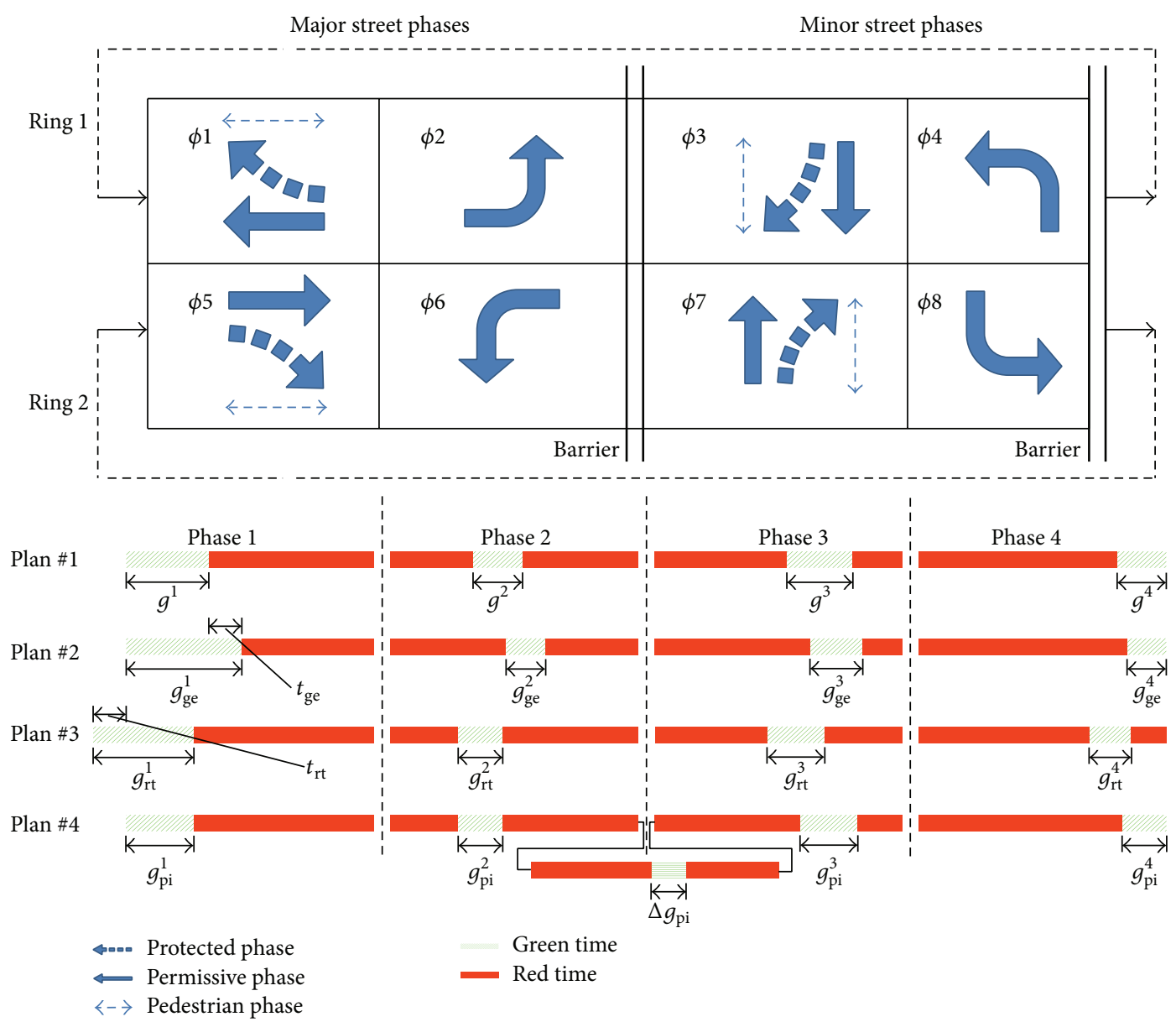

FIGURE 4: Ring-and-barrier diagram and TSP strategies.

route $m$ at bus stops. The passenger delay for each arriving transit vehicle at bus stops can be formulated in the following equation which includes the waiting time delay including the passenger waiting time of all buses which are served at stop bay:

$$
\begin{aligned}
d_{s} & =\sum_{m \in M} \sum_{n \in N}\left(\int_{0}^{t_{f}^{m n}}\left(t_{f}^{m n}-t\right) h^{m n}(t) d t\right. \\
& \left.-\int_{0}^{t_{s}^{m n}}\left(t_{s}^{m n}-t\right) k^{m n}(t) d t\right) .
\end{aligned}
$$

2.2. Signal Phase Allocation Method. Figure 4 illustrates a sample four-phase ring diagram with three transit signal priority strategies including the green extension, red truncation, and phase insertion. Phase 1 includes a through and right movement for vehicles and a through movement for pedestrians on the major street. Phase 2 includes a left-turn movement for the main street. Phase 3 consists of a through and right movement for vehicles and a through movement for pedestrians on the minor street. Finally, Phase 4 has one leftturn phase on the minor street. The bus movements follow the through movement in the major direction. The original phase plan without TSP is Plan 1. Plan 2 is the TSP-based phase plan with green phase extension where $t_{\mathrm{ge}}$ is the duration of green time extension for bus priority. Plan 3 is the TSP phase plan of the red phase truncation, where $t_{\mathrm{rt}}$ is the duration of the red time truncation. Plan 4 is the TSP plan with phase insertion where Phase 1 green time is split into $\Delta g_{\mathrm{pi}}$ and $g_{\mathrm{pi}}^{1}$.

In this study, we assume that the cycle length is constant, and the phase plan is predetermined and fixed. Signal phasing plans with three TSP strategies including the green extension, red truncation, and phase insertion are selected based on their priority rules. The green time duration of the three TSP scenarios for transit vehicles is calculated by the following equations:

$$
\begin{aligned}
& g_{\mathrm{ge}}^{j}= \begin{cases}g^{j}+t_{\mathrm{ge}} & j=a \\
g^{j}\left(1-\frac{t_{\mathrm{ge}}}{C-L-g^{a}}\right) & j \neq a,\end{cases} \\
& g_{\mathrm{rt}}^{j}= \begin{cases}t_{\mathrm{rt}}+g^{j}\left(1-\frac{t_{\mathrm{rt}}}{C-L}\right) & j=b+1 \\
g^{j}\left(1-\frac{t_{\mathrm{rt}}}{C-L}\right) & j \neq b+1,\end{cases} \\
& g_{\mathrm{pi}}^{j}=g^{j}\left(1-\frac{\Delta g_{\mathrm{pi}}+\Delta y_{\mathrm{pi}}}{C-L}\right),
\end{aligned}
$$




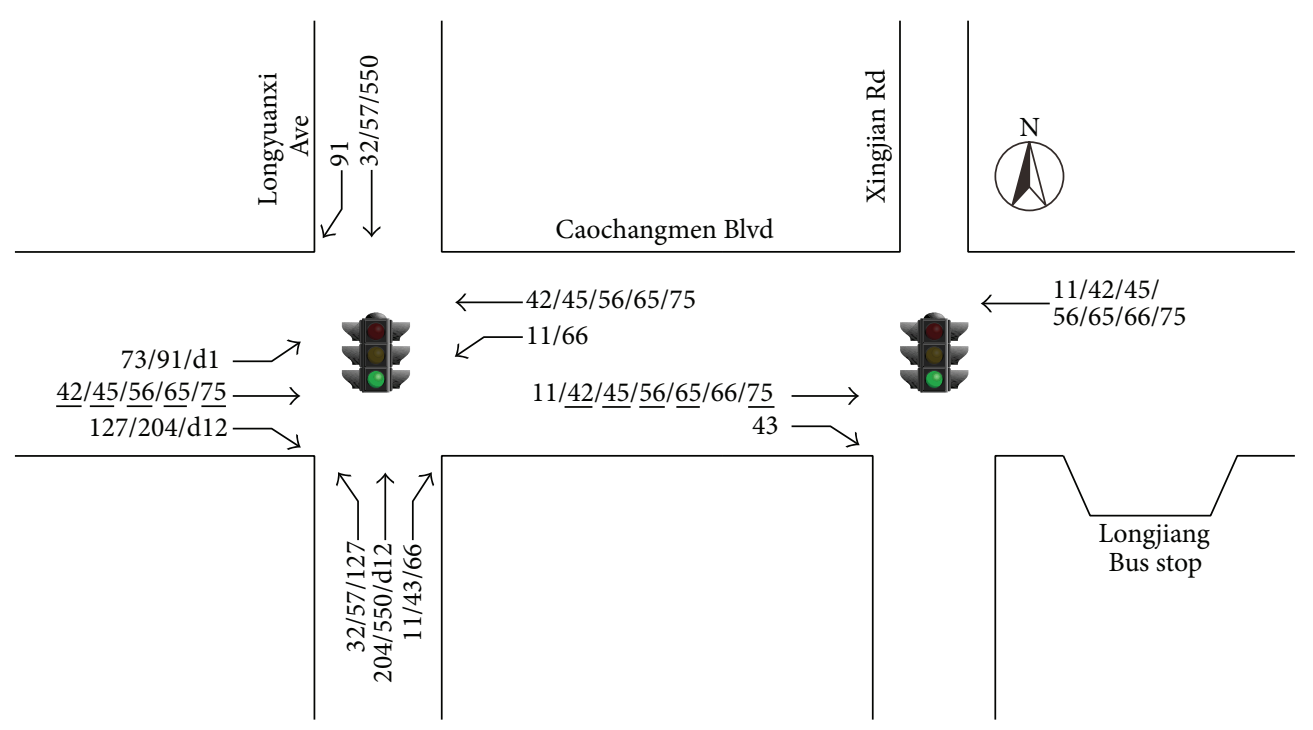

FIGURE 5: Layouts and bus routes of test bus stop-to-stop segment.

where $a$ is the green time extension and $b$ is the red time truncation. $L$ is the lost time in each cycle of the original phasing plan without TSP control. $g^{j}, g_{\mathrm{ge}}^{j}, g_{\mathrm{rt}}^{j}$, and $g_{\mathrm{pi}}^{j}$ are the green times of the original phasing plan without TSP control, the TSP plan with the green extension, the TPS plan with the red truncation, and the TSP plan with the phase insertion in phase $j$, respectively. $\Delta y_{\mathrm{pi}}$ is the yellow time of phase insertion TSP plan for the insertion phase.

2.3. Genetic Algorithm Solution. Genetic algorithms (GAs) are the heuristic optimization methods based on the mechanisms of natural selection and evolution [26]. GA cannot guarantee global optimal solution but can reach relatively optimal solution with reasonable time. In this paper, GA is applied to optimize the signal timing plans in the proposed biobjective optimization framework for TSP problems. The biobjective optimization framework is generated by using Genetic Algorithm Toolbox of MATLAB R2014a.

\section{Evaluation}

3.1. Experiment Design. In this study, field data collected from Caochangmen Boulevard in Nanjing, China, are used in the numerical experiments for the proposed TSP models. The Caochangmen Boulevard is a major commuting arterial corridor. Figure 5 shows the stop-to-stop segment for TSP optimization. The segment has two adjacent signalized intersections (Caochangmen Boulevard at Longyuanxi Avenue and at Xingjian Street), one bus stop (Longjiang Stop), and seventeen bus routes (Bus routes 11, 32, 42, 43, 45, 56, 57, 65, 66, 73, $75,91,127,204,550, d 1$, and d12). In this study, transit signal priority (TSP) strategies are developed to respond to morning peak hour direction, the eastbound direction. The bus routes considered are routes $42,45,56,65$, and 75 as underlined in the figure. These five EB bus routes have an average headway of 5-8 minutes during the morning rush hour.
3.1.1. Intersection. The geometric layout of the intersection of Caochangmen Boulevard and Longyuanxi Avenue is illustrated in Figure 6.

The eastbound and westbound approaches have three through lanes, one exclusive right-turn lane, and one exclusive left-turn lane. The northbound and southbound approaches have one through lane, one exclusive right-turn lane, and one exclusive left-turn lane. Average traffic volumes in the morning rush hour (7-8 a.m.) are shown in Table 1 in 15 minute intervals. The flow data are collected during six days from May 19 to May 21, 2015, and April 12 to April 14, 2016.

Figure 6 illustrates an original signal phase plan (without TSP strategy) for the intersection of Caochangmen Boulevard and Longyuanxi Avenue. The cycle of this intersection signal phase is 160 seconds. Phase 1 is provided for the EB and WB through movements for vehicles, pedestrians, and bicycles. Phase 2 is the right-turn phase for all approaches. Phases 3 and 5 are, respectively, the left-turn phases for Caochangmen Boulevard and Longyuanxi Avenue. Phase 4 is provided for the NB and SB through movements for all travel modes.

The geometric conditions and traffic volumes for the intersection of Caochangmen Boulevard and Xingjian Street are demonstrated in Figure 7 and Table 2. The westbound approach has two through lanes, one shared through/rightturn lane, and two exclusive left-turn lanes. The eastbound approach has three through lanes, one exclusive right-turn lane, and one exclusive left-turn lane. The northbound approach has one through lane, one exclusive right-turn lane, and one exclusive left-turn lane. The southbound approach is a one-way street only allowing NB traffic.

Figure 7 illustrates the original signal phase plan (without TSP strategy) for the intersection of Caochangmen Boulevard and Xingjian Street. The cycle of this intersection signal phase is 160 seconds. Phase 1 is provided for the EB and WB through movements. Phase 2 is the right-turn phase for all approaches. Phase 3 is the left-turn phase for EB and WB approaches. Phase 4 is provided for the northbound and southbound 
TABLE 1: Traffic volumes for the intersection of Caochangmen Blvd and Longyuanxi Ave.

\begin{tabular}{|c|c|c|c|c|c|c|c|c|c|}
\hline & & LT veh (veh) & TH veh (veh) & RT veh (veh) & LT bus (bus) & TH bus (bus) & RT bus (bus) & Ped (ped) & Bic (bic) \\
\hline \multirow{4}{*}{$7: 00-7: 15$} & $\mathrm{~EB}$ & 44 & 272 & 65 & 7 & 12 & 6 & 155 & 158 \\
\hline & WB & 27 & 81 & 37 & 5 & 10 & NA & 77 & 95 \\
\hline & SB & 50 & 47 & 71 & NA & 6 & 3 & 99 & 141 \\
\hline & NB & 31 & 56 & 60 & 7 & 7 & 8 & 72 & 123 \\
\hline \multirow{4}{*}{$7: 15-7: 30$} & $\mathrm{~EB}$ & 47 & 275 & 73 & 7 & 13 & 7 & 201 & 197 \\
\hline & WB & 43 & 79 & 49 & 5 & 11 & NA & 61 & 111 \\
\hline & SB & 47 & 75 & 79 & NA & 6 & 3 & 161 & 195 \\
\hline & $\mathrm{NB}$ & 43 & 68 & 65 & 7 & 9 & 6 & 127 & 171 \\
\hline \multirow{4}{*}{$7: 30-7: 45$} & $\mathrm{~EB}$ & 56 & 324 & 78 & 6 & 11 & 8 & 210 & 261 \\
\hline & WB & 31 & 124 & 56 & 4 & 11 & NA & 92 & 172 \\
\hline & SB & 57 & 73 & 90 & NA & 9 & 2 & 198 & 301 \\
\hline & NB & 56 & 69 & 82 & 4 & 8 & 8 & 101 & 184 \\
\hline \multirow{4}{*}{$7: 45-8: 00$} & $\mathrm{~EB}$ & 51 & 301 & 79 & 5 & 12 & 6 & 149 & 222 \\
\hline & WB & 44 & 88 & 53 & 5 & 10 & NA & 100 & 192 \\
\hline & SB & 51 & 58 & 70 & NA & 7 & 3 & 161 & 231 \\
\hline & $\mathrm{NB}$ & 50 & 56 & 77 & 8 & 9 & 7 & 142 & 199 \\
\hline
\end{tabular}
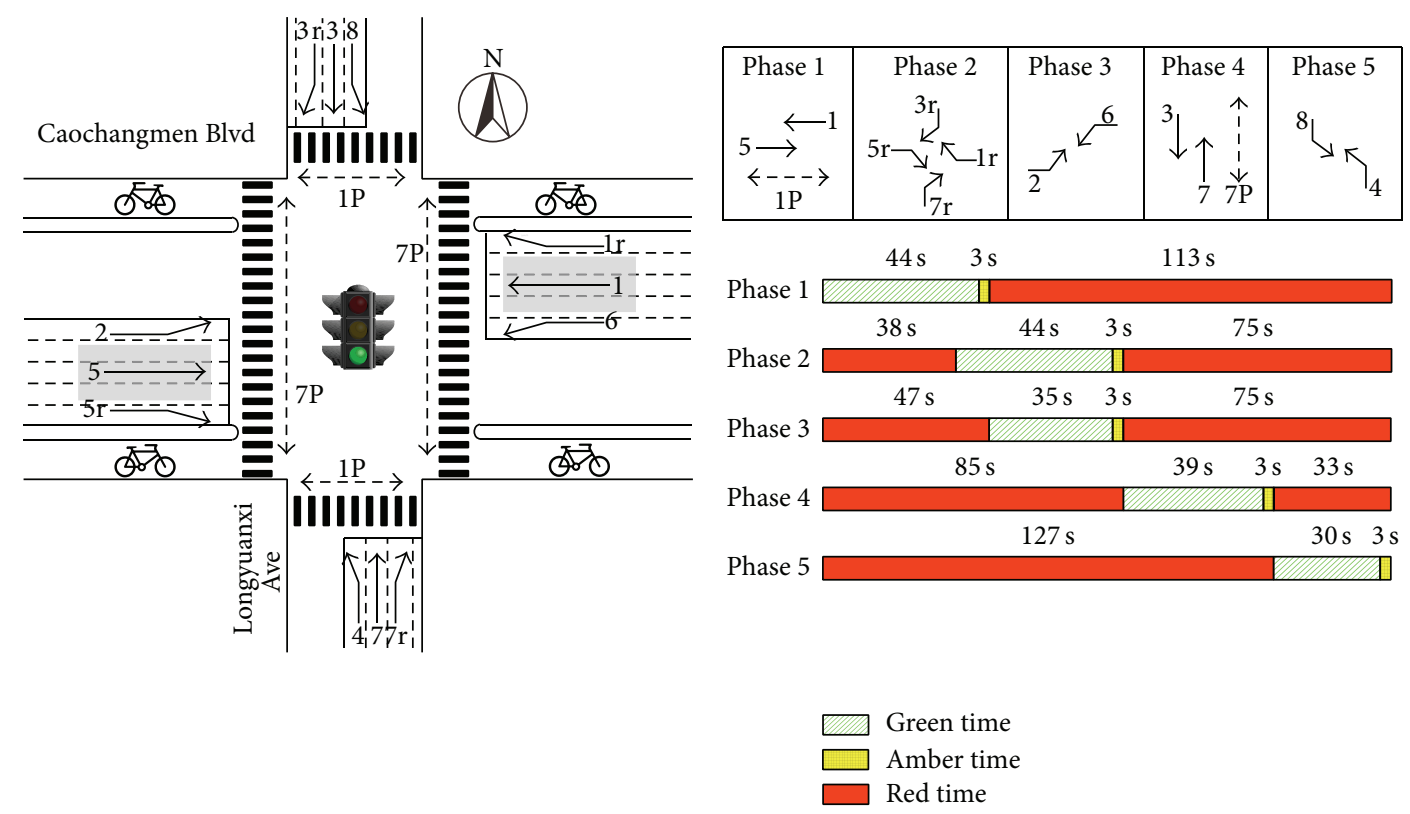

FIgURE 6: Layouts and phasing for the intersection of Caochangmen Blvd and Longyuanxi Ave.

through and left-turn movements of vehicles, pedestrians, and bicycles.

Several preliminary experiments were performed to determine the lane capacity which is 1700 vehicles per lane per hour approximately [27], and the bus lane capacity is approximately 850 buses per lane per hour [28].

The average passenger occupancy of general vehicles at these two intersections during rush hour is observed to be at 1.8 persons per vehicle in field observations. Passenger occupancy of these bus routes is estimated based on automated passenger count (APC) data and the empirical calculation of Nanjing Transit Agency. Table 3 lists the average passenger occupancy of all transit routes during the test days at the different approaches of the two intersections.
3.1.2. Bus Stop. The deviation of the actual arrival time from scheduled time (DAT) and dwelling time (DT) of transit routes $42,45,56,65$, and 75 at Longjiang Bus Stop is shown in Figure 8. Arrival time data are acquired from the Automatic Vehicle Location (AVL) system between 7:00 a.m. and 8:00 a.m. during six days from May 19 to May 21, 2015, and April 12 to April 14, 2016. Passenger occupancy (PO), the number of boarding passengers (BP), and alighting passengers (AP) in the morning rush hour in the same period are depicted in Figure 9. The passenger occupancy is calculated based on automated passenger count (APC) data and the empirical observations of local Transit Agency. The boarding and alighting passenger count data are collected through the observation at the bus stops. 
TABLE 2: Traffic volumes for the intersection of Caochangmen Blvd and Xingjian St.

\begin{tabular}{|c|c|c|c|c|c|c|c|c|c|}
\hline & & LT veh (veh) & TH veh (veh) & RT veh (veh) & LT bus (bus) & TH bus (bus) & RT bus (bus) & Ped (ped) & Bic (bic) \\
\hline \multirow{4}{*}{$7: 00-7: 15$} & $\mathrm{~EB}$ & 22 & 316 & 44 & NA & 16 & 3 & 181 & 231 \\
\hline & WB & 92 & 111 & 19 & NA & 15 & NA & 55 & 128 \\
\hline & SB & NA & NA & NA & NA & NA & NA & 171 & 245 \\
\hline & $\mathrm{NB}$ & & 60 & 111 & NA & NA & NA & 141 & 204 \\
\hline \multirow{4}{*}{ 7:15-7:30 } & $\mathrm{EB}$ & 23 & 327 & NA & 17 & 2 & 198 & 260 & 241 \\
\hline & WB & 101 & 125 & NA & 16 & NA & 60 & 141 & 136 \\
\hline & SB & NA & NA & NA & NA & NA & 211 & 279 & 262 \\
\hline & NB & & 72 & 122 & NA & NA & NA & 181 & 221 \\
\hline \multirow{4}{*}{$7: 30-7: 45$} & $\mathrm{~EB}$ & 33 & 371 & NA & 16 & 3 & 261 & 324 & 311 \\
\hline & WB & 111 & 143 & NA & 15 & NA & 70 & 149 & 154 \\
\hline & SB & NA & NA & NA & NA & NA & 221 & 299 & 295 \\
\hline & $\mathrm{NB}$ & & 93 & 141 & NA & NA & NA & 159 & 229 \\
\hline \multirow{4}{*}{$7: 45-8: 00$} & $\mathrm{~EB}$ & 35 & 347 & NA & 16 & 3 & 241 & 265 & 285 \\
\hline & WB & 103 & 132 & NA & 15 & NA & 60 & 149 & 132 \\
\hline & SB & NA & NA & NA & NA & NA & 187 & 260 & 259 \\
\hline & $\mathrm{NB}$ & & 69 & 130 & NA & NA & NA & 166 & 211 \\
\hline
\end{tabular}
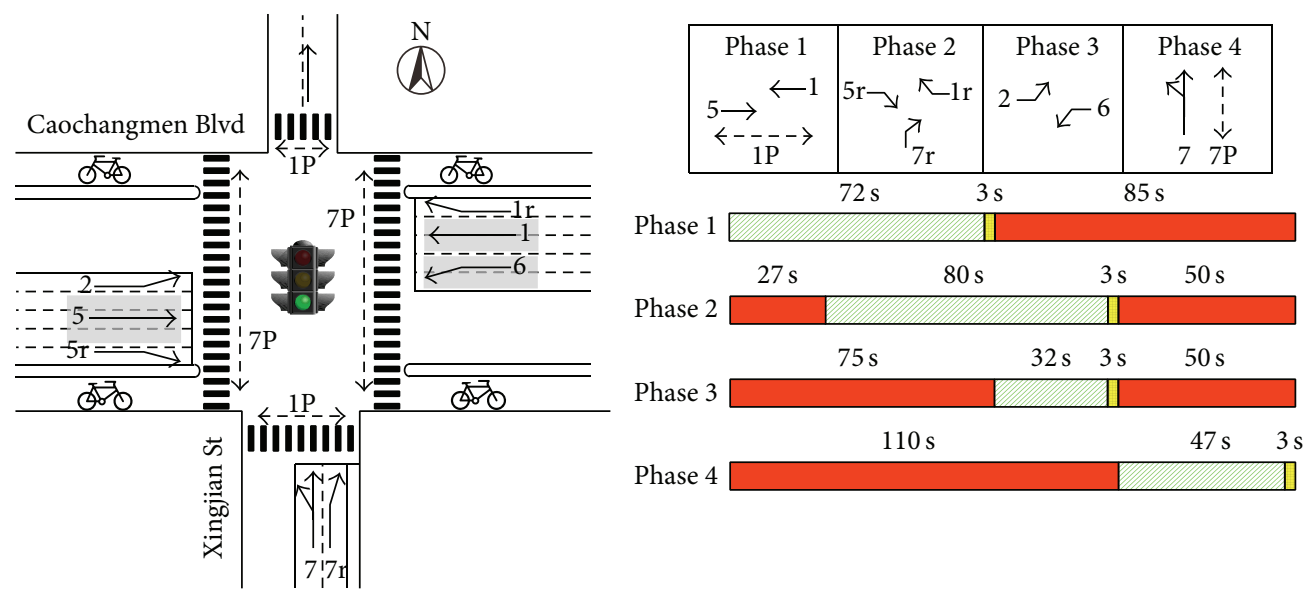

Green time

Amber time

Red time

FIgURE 7: Layouts and phasing plan for the intersection of Caochangmen Blvd and Xingjian St.

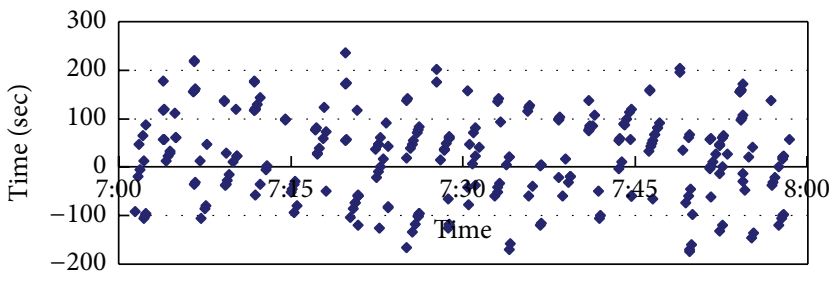

(a) DAT

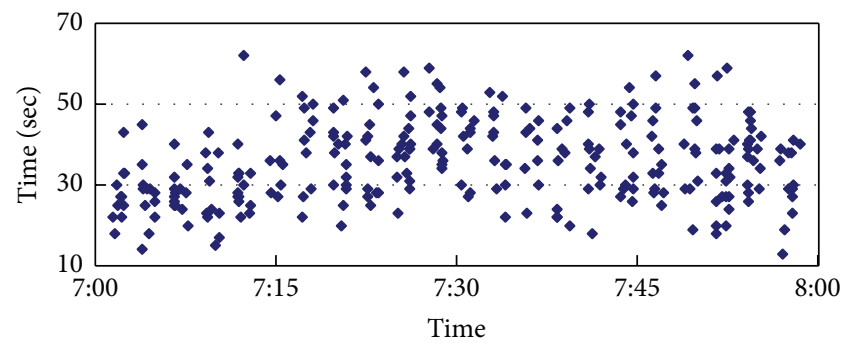

(b) DT

Figure 8: DAT and DT of transit at Longjiang bus stop in the morning rush hour during six days from May 19 to May 21, 2015, and April 12 to April 14, 2016. 


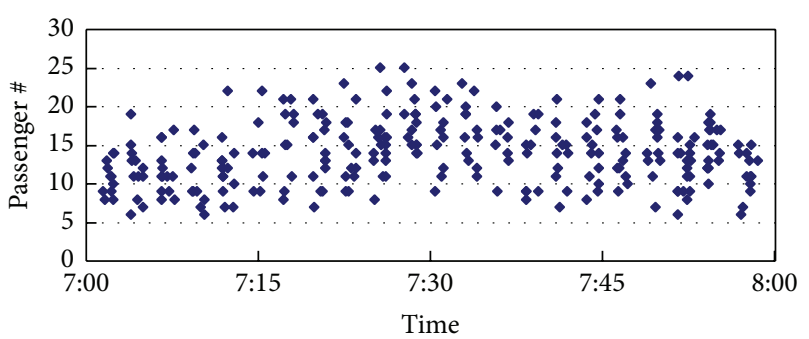

(a) BP

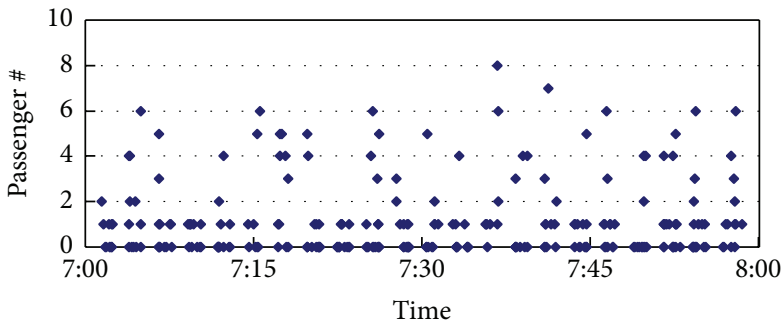

(b) AP

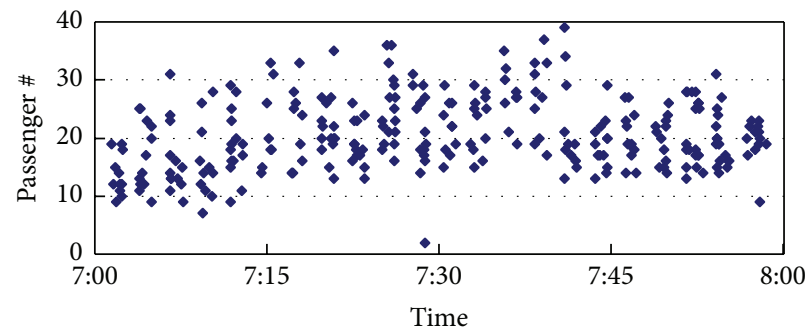

(c) $\mathrm{PO}$

FIGURE 9: BP, AP, and PO of passengers at Longjiang bus stop in the morning rush hour during six days from May 19 to May 21,2015 , and April 12 to April 14, 2016.

TABLE 3: Average passenger occupancy of transit vehicle at approaches of intersections.

\begin{tabular}{|c|c|c|c|c|c|c|c|c|c|}
\hline & \multicolumn{4}{|c|}{$\begin{array}{c}\text { Intersection of } \\
\text { Caochangmen } \\
\text { Blvd and } \\
\text { Longyuanxi Ave }\end{array}$} & \multicolumn{4}{|c|}{$\begin{array}{c}\text { Intersection of } \\
\text { Caochangmen } \\
\text { Blvd and } \\
\text { Xingjian St }\end{array}$} \\
\hline & & EB & WB & SB & $\mathrm{NB}$ & $\mathrm{EB}$ & WB & SB & NB \\
\hline \multirow{3}{*}{$7: 00-7: 15$} & $\mathrm{LT}$ & 13.9 & 8.8 & NA & 9.9 & NA & NA & NA & NA \\
\hline & $\mathrm{TH}$ & 15.1 & 13.9 & 21.1 & 18.4 & 16.1 & 13.5 & NA & NA \\
\hline & $\mathrm{RT}$ & 15.9 & NA & 11.6 & 9.2 & 8.1 & NA & NA & NA \\
\hline \multirow{3}{*}{$7: 15-7: 30$} & LT & 14.8 & 11.1 & NA & 13.1 & NA & NA & NA & NA \\
\hline & $\mathrm{TH}$ & 23.4 & 16.9 & 26.3 & 23.9 & 22.5 & 15.8 & NA & NA \\
\hline & $\mathrm{RT}$ & 19.8 & NA & 16.1 & 10.5 & 11.1 & NA & NA & NA \\
\hline \multirow{3}{*}{$7: 30-7: 45$} & LT & 17.2 & 12.2 & NA & 15.1 & NA & NA & $\mathrm{NA}$ & $\mathrm{NA}$ \\
\hline & $\mathrm{TH}$ & 23.6 & 19.5 & 28.6 & 24.9 & 22.9 & 16.4 & NA & NA \\
\hline & RT & 19.9 & NA & 18.5 & 12.5 & 13.8 & NA & NA & NA \\
\hline \multirow{3}{*}{$7: 45-8: 00$} & $\mathrm{LT}$ & 18.5 & 10.7 & NA & 14.7 & NA & NA & $\mathrm{NA}$ & $\mathrm{NA}$ \\
\hline & $\mathrm{TH}$ & 21.3 & 18.5 & 27.8 & 27.1 & 19.9 & 17.2 & NA & NA \\
\hline & RT & 23.4 & NA & 18.4 & 11.2 & 13.3 & NA & NA & NA \\
\hline
\end{tabular}

The number of BP is higher than AP at Longjiang bus stop in the morning rush hour for the five bus routes, and the number of BP directly affects the duration of dwell time of buses in the morning rush hour.

\subsection{Experimental Results and Analysis}

3.2.1. Experimental Design. The numerical experiment is conducted with the following three assumptions:

(1) The capacities for each approach of signalized intersections are fixed and not affected by traffic operations.
(2) Uniform arrivals of bicycles and pedestrians are assumed during each 15 minutes of the morning rush hour.

(3) Uniform arrival rates are also assumed for passengers coming to Longjiang bus stop during each 15 minutes of the morning rush hour.

Several preliminary experiments were performed to determine the best operational parameters for the GA optimizer used in this study. Results from those experiments led to the selection of the following GA parameters:

(i) Population of 300 individuals.

(ii) Mutation rate of $0.1 \%$.

(iii) Crossover rate of $70 \%$.

(iv) Chromosome length of 4.

(v) Generation number of 50.

The field data collected from Caochangmen Boulevard (in Nanjing, China) are used to build the bus operational scenarios. The proposed biobjective optimization framework is solved by the Genetic Algorithm Toolbox of MATLAB R2014a. The optimization variables are the durations of TSP green times at the two intersections. Table 4 presents the passenger delay at the segment, the delay deviation at the bus stop, and the maximum degree of saturation for the approaches at the two intersections with and without TSP optimization.

The optimized phasing plans of the green extension, red truncation, and phase insertion TSP strategies are generated by using the signal phasing allocation methods. The optimized TSP phasing plans for the three strategies at two intersections of this segment are presented in Figures 10 and 11. 
TABLE 4: Solutions of biobjective model.

\begin{tabular}{|c|c|c|c|c|c|c|}
\hline & \multicolumn{2}{|c|}{$\begin{array}{c}\text { Intersection of } \\
\text { Caochangmen Blvd and } \\
\text { Longyuanxi Ave }\end{array}$} & \multicolumn{2}{|c|}{$\begin{array}{c}\text { Intersection of } \\
\text { Caochangmen Blvd and } \\
\text { Xingjian St }\end{array}$} & \multicolumn{2}{|c|}{ Longjiang bus stop } \\
\hline & $\begin{array}{l}\text { Original } \\
\text { plan }\end{array}$ & $\begin{array}{l}\text { Optimal } \\
\text { plan }\end{array}$ & $\begin{array}{c}\text { Original } \\
\text { plan }\end{array}$ & $\begin{array}{c}\text { Optimal } \\
\text { plan }\end{array}$ & Original plan & Optimal plan \\
\hline Duration of TSP green time $(\mathrm{sec})$ & 0 & 7 & 0 & 18 & NA & NA \\
\hline Passenger delay (sec) & $1,232,399$ & $1,122,171$ & 549,584 & 495,446 & 130,696 & 119,293 \\
\hline Delay deviation (sec) & NA & NA & NA & NA & 59,274 & 50,232 \\
\hline Maximum saturation degree of approaches (\%) & $83.1 \%$ & $90 \%$ & $72.3 \%$ & $87.4 \%$ & NA & NA \\
\hline
\end{tabular}
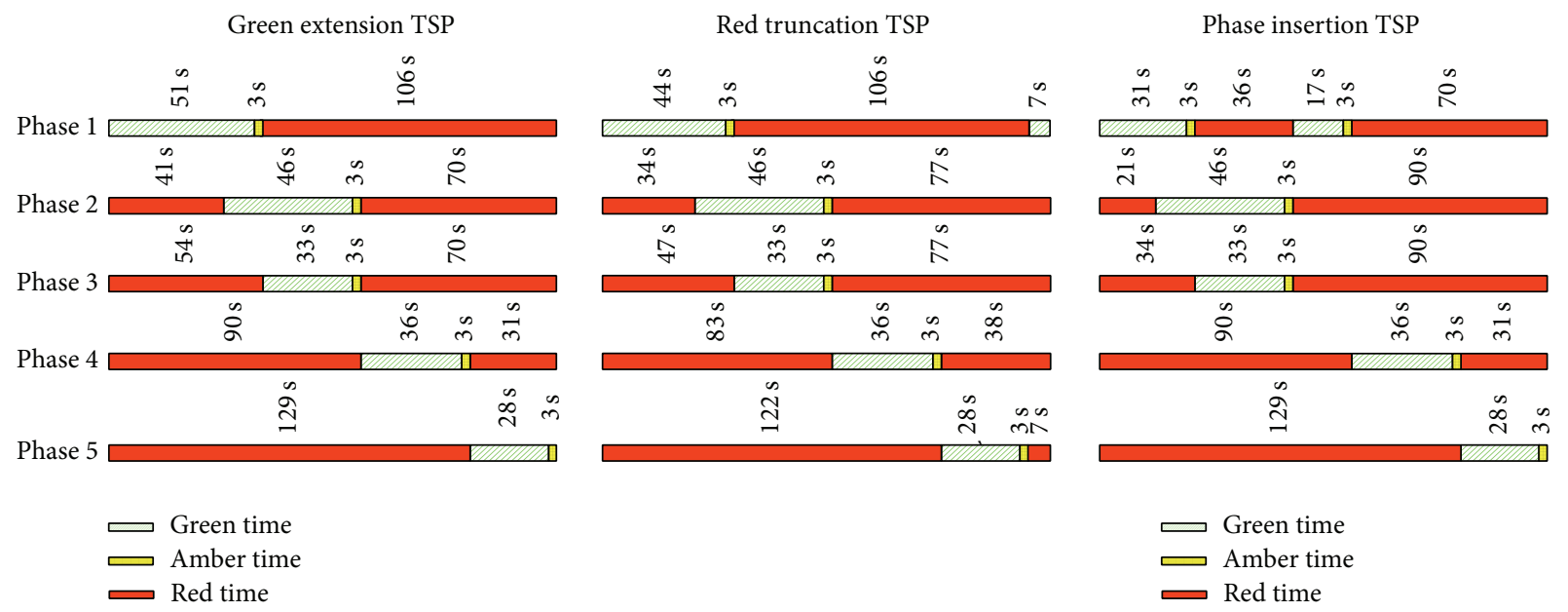

凹 Amber time

Red time

FIgURE 10: Three TSP plans for the intersection of Caochangmen Blvd and Longyuanxi Ave.
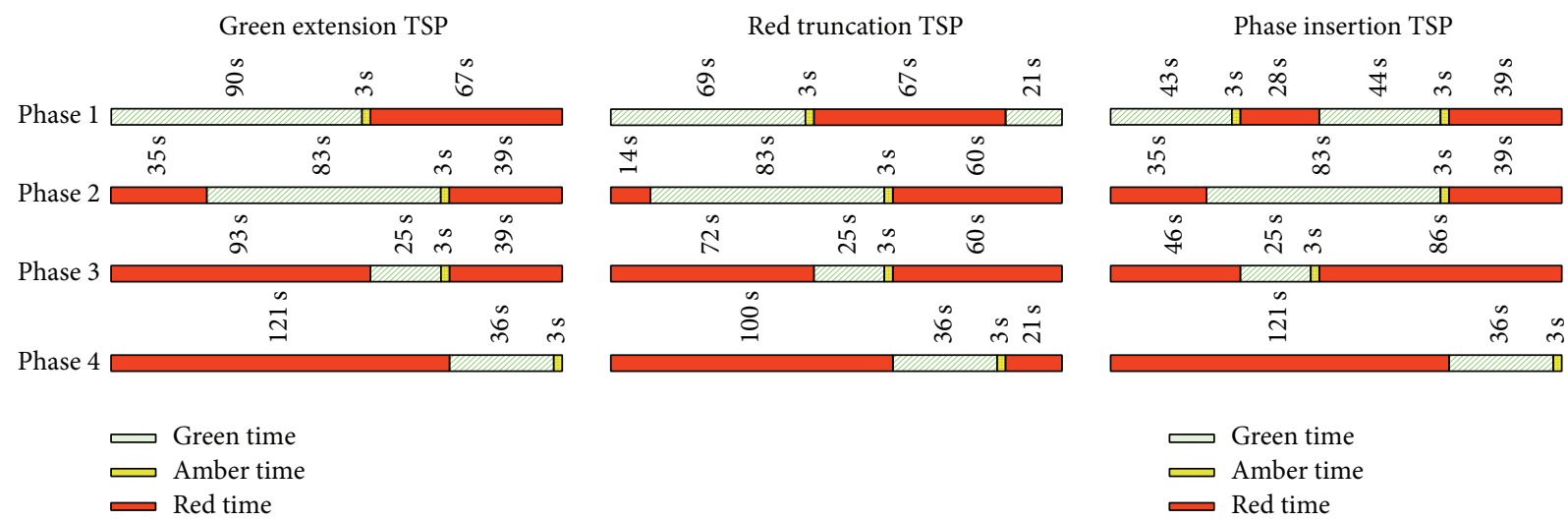

FIgURE 11: Three TSP plans for the intersection of Caochangmen Blvd and Xingjian St.

3.2.2. Results Simulation Analysis. VISSIM-based simulation platform (Figure 12) is established. Four phasing plans including the non-TSP, TSP with green extension, TSP with red truncation, and TSP with phase insertion are simulated.

The passenger delay at the intersections and bus stops of this experimental segment is calculated based on simulationbased average vehicle delay, observation-based traffic volume, and observation-based occupancy. Table 5 summarizes the passenger delay at the intersection of Caochangmen Boulevard at Longyuanxi Avenue intersection (ID1), and Caochangmen Boulevard at Xingjian Street (ID2), the
Longjiang bus stop (SD), the stop-to-stop segment (TD), and the delay deviation at the bus stop (DD) for the four signal phasing plans.

Figure 13 illustrates the passenger delay and the deviation reduction ratio of the three TSP strategies compared with the original non-TSP signal phasing plan at the experimental segment in the morning rush hour.

The results of Figure 13 demonstrate the significant reduction of over $6 \%$ in passenger delay and over $8 \%$ in schedule deviation at the test segment. The three TSP scenarios can significantly decrease passenger travel time on the targeted 
TABLE 5: Total passenger delay of bus stop-to-stop segment for four signal plans.

\begin{tabular}{|c|c|c|c|c|c|}
\hline & & $7: 00-7: 15$ & $7: 15-7: 30$ & $7: 30-7: 45$ & $7: 45-8: 00$ \\
\hline \multirow{5}{*}{ Original signal phasing plan } & ID1 & $255,632.62$ & $354,305.07$ & $445,548.88$ & $400,597.01$ \\
\hline & ID2 & $120,831.26$ & $150,246.35$ & $168,946.81$ & $155,727.78$ \\
\hline & $\mathrm{SD}$ & $25,991.75$ & $58,813.46$ & $33,122.80$ & $42,280.39$ \\
\hline & $\mathrm{TD}$ & $402,455.62$ & $563,364.88$ & $647,618.48$ & $598,605.18$ \\
\hline & $\mathrm{DD}$ & $12,306.59$ & $25,762.68$ & $12,525.26$ & $14,347.02$ \\
\hline \multirow{5}{*}{ Green extension TSP-based phasing plan } & ID1 & $240,805.52$ & $339,377.82$ & $405,153.62$ & $363,689.02$ \\
\hline & ID2 & $106,106.33$ & $130,151.06$ & $157,475.55$ & $136,351.30$ \\
\hline & $\mathrm{SD}$ & $23,362.84$ & $55,153.52$ & $30,436.76$ & $38,112.66$ \\
\hline & $\mathrm{TD}$ & $370,274.68$ & $524,682.41$ & $593,065.93$ & $538,152.98$ \\
\hline & $\mathrm{DD}$ & $10,321.75$ & $23,299.40$ & $10,754.42$ & $11,148.19$ \\
\hline \multirow{5}{*}{ Red truncation TSP-based phasing plan } & ID1 & $242,338.86$ & $339,006.11$ & $403,503.98$ & $362,183.64$ \\
\hline & ID2 & $105,240.25$ & $133,129.12$ & $155,605.78$ & $137,718.48$ \\
\hline & $\mathrm{SD}$ & $22,731.09$ & $55,771.61$ & $31,093.79$ & $37,802.44$ \\
\hline & TD & $370,310.20$ & $527,906.83$ & $590,203.56$ & $537,704.56$ \\
\hline & $\mathrm{DD}$ & $9,569.88$ & $23,757.92$ & $11,288.38$ & $10,741.80$ \\
\hline \multirow{5}{*}{ Phase insertion TSP-based phasing plan } & ID1 & $229,476.15$ & $342,305.37$ & $412,606.35$ & $370,422.89$ \\
\hline & ID2 & $99,040.30$ & $134,415.23$ & $165,700.06$ & $140,838.86$ \\
\hline & $\mathrm{SD}$ & $20,791.99$ & $53,189.93$ & $29,334.46$ & $35,772.74$ \\
\hline & $\mathrm{TD}$ & $349,308.43$ & $529,910.53$ & $607,640.86$ & $547,034.49$ \\
\hline & $\mathrm{DD}$ & $8,194.10$ & $22,165.39$ & $10,050.99$ & $9,348.03$ \\
\hline
\end{tabular}

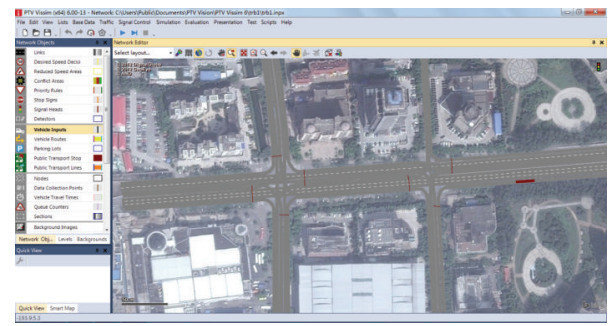

FIGURE 12: Simulation platform interface.

major bus routes and improve the schedule reliability of the transit system. The performances of the TSP plans with the green extension and red truncation are similar in reducing passenger delay and schedule deviation. TSP plans with the green extension and red truncation have advantages in decreasing total passenger delay at bus stop-to-stop segment over TSP plans with phase insertion with over $2 \%$ more reduction, while the latter performs better in reducing delay deviation at the bus stop with over $5 \%$ more reduction than the TSP plans with the green extension and red truncation. Therefore, GE plan and RT plan perform better in segment total delay reduction, while PI plan performs better in delay deviation reduction at bus stop.

In addition, the performance of three optimized TSP plans varies in different saturation conditions. Traffic volume of Caochangmen Boulevard (west-east) between the two intersections in morning rush hour is computed at $1841 \mathrm{pcu}$ according to the data in Tables 1 and 2. The reduction rates at different 15-minute intervals in the morning rush hour are different. The performance of the TSP strategies does not perform as well as those in the first and the last 15-minute periods. Therefore, the three TSP scenarios for reducing delay and improving the reliability of transit system will be weakened under saturated and oversaturated flow condition.

\section{Conclusion}

This paper presents a biobjective TSP optimization framework that can provide effective priority control for transit requests, while minimizing the total passenger delay on each stop-to-stop segment (including both adjacent signalized intersections and downstream bus stops) and the schedule deviation at bus stops. The biobjective optimization model is presented to calculate the duration of the allocated transit green time, and the signal phasing allocation method is proposed to generate TSP phasing plans. A numerical experiment is conducted by simulating bus operations with field volume and phasing data collected at one segment of Caochangmen Boulevard, in Nanjing, China. The original non-TSP phasing plan, optimized TSP phasing plan with the green extension, red truncation, and phase insertion strategies are simulated and evaluated using the VISSIM simulation platform. The case study results validate the effectiveness of the proposed framework, and the performance of the three transit signal priority plans is analyzed and evaluated under different traffic demand patterns during the morning rush hour.

Future work includes more extensive numerical experiments or field tests to assess the effectiveness of the proposed model under the interactive effect between intersections and bus stops. Another potential extension is to expand towards urban traffic network for systematic improvement of 


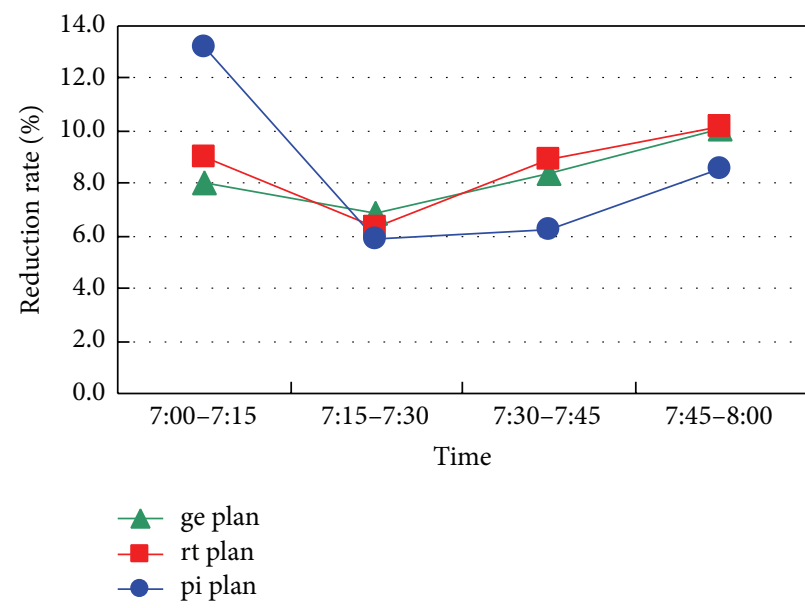

(a) Total segment delay reduction

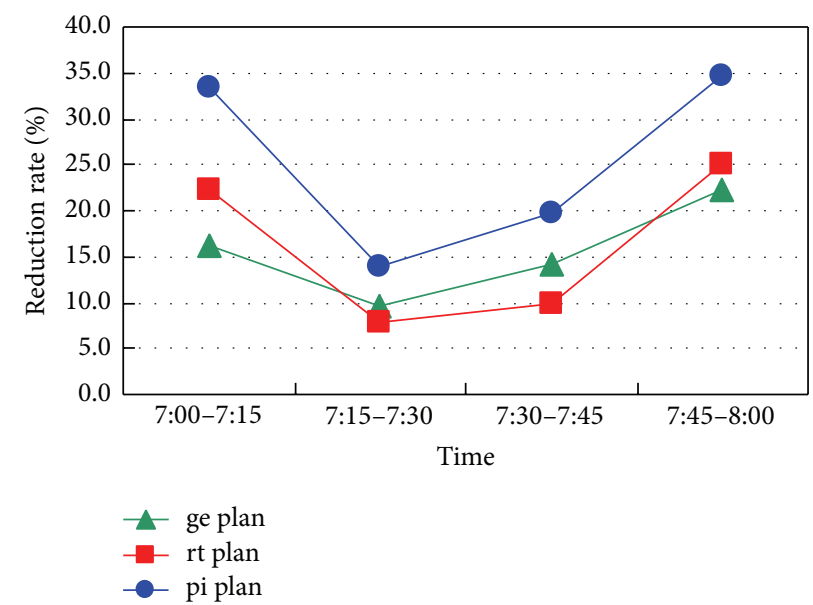

(b) Delay deviation reduction

FIGURE 13: The comparisons of TSP plans for delay reduction ratio in the morning rush hour.

the efficiency and reliability of transit system while minimizing the negative impact on general vehicles under complex traffic condition.

\section{Competing Interests}

The authors declare that there is no conflict of interests regarding the publication of this paper.

\section{Acknowledgments}

This research was supported by the National Natural Science Foundation of China (Grant no. 51508161), Natural Science Foundation of Jiangsu Province (Grant no. BK20140851), and Fundamental Research Funds for the Central Universities of China (Grant no. 2013B01314).

\section{References}

[1] W. Smith, Westinghouse Airbrake Company, and Institute of Public Administration, Study of Evolutionary Urban Transportation, vol. 1-3, U.S. Department of Housing and Urban Development, 1968.

[2] F. Dion and B. Hellinga, "A rule-based real-time traffic responsive signal control system with transit priority: application to an isolated intersection," Transportation Research Part B: Methodological, vol. 36, no. 4, pp. 325-343, 2002.

[3] E. Christofa and A. Skabardonis, "Traffic signal optimization with application of transit signal priority to an isolated intersection," Transportation Research Record, no. 2259, pp. 192-201, 2011.

[4] F. Dion, H. Rakha, and Y. Zhang, "Evaluation of potential transit signal priority benefits along a fixed-time signalized arterial," Journal of Transportation Engineering, vol. 130, no. 3, pp. 294303, 2004.

[5] M. Vasudevan, Robust Optimization Model for Bus Priority under Arterial Progression, University of Maryland, College Park, Md, USA, 2005.
[6] M. Mesbah, M. Sarvi, and G. Currie, "Optimization of transit priority in the transportation network using a genetic algorithm," IEEE Transactions on Intelligent Transportation Systems, vol. 12, no. 3, pp. 908-919, 2011.

[7] W. Kim and L. R. Rilett, "Improved transit signal priority system for networks with nearside bus stops," Transportation Research Record, no. 1925, pp. 205-214, 2005.

[8] W. Ma, W. Ni, L. Head, and J. Zhao, "Effective coordinated optimization model for transit priority control under arterial progression," Transportation Research Record, no. 2356, pp. 7183, 2013.

[9] W. Feng, Analyses of bus travel time reliability and transit signal priority at the stop-to-stop segment level [Ph.D. thesis], Portland State University, 2014.

[10] W. Ma, Y. Liu, and X. Yang, "A dynamic programming approach for optimal signal priority control upon multiple high-frequency bus requests," Journal of Intelligent Transportation Systems: Technology, Planning, and Operations, vol. 17, no. 4, pp. 282-293, 2013.

[11] M. Li, Y. Yin, W.-B. Zhang, K. Zhou, and H. Nakamura, "Modeling and implementation of adaptive transit signal priority on actuated control systems," Computer-Aided Civil and Infrastructure Engineering, vol. 26, no. 4, pp. 270-284, 2011.

[12] E. Christofa, I. Papamichail, and A. Skabardonis, "Personbased traffic responsive signal control optimization," IEEE Transactions on Intelligent Transportation Systems, vol. 14, no. 3, pp. 1278-1289, 2013.

[13] P. Furth and T. Muller, "Conditional bus priority at signalized intersections: better service quality with less traffic disruption," Transportation Research Record, no. 1731, pp. 23-30, 2000.

[14] N. Hounsell and B. Shrestha, "A new approach for co-operative bus priority at traffic signals," IEEE Transactions on Intelligent Transportation Systems, vol. 13, no. 1, pp. 6-14, 2012.

[15] X. Zeng, Y. Zhang, K. N. Balke, and K. Yin, "A real-time transit signal priority control model considering stochastic bus arrival time," IEEE Transactions on Intelligent Transportation Systems, vol. 15, no. 4, pp. 1657-1666, 2014.

[16] W. Gu, Y. Li, M. J. Cassidy, and J. B. Griswold, "On the capacity of isolated, curbside bus stops," Transportation Research Part B: Methodological, vol. 45, no. 4, pp. 714-723, 2011. 
[17] X. Yang, Z. Gao, X. Zhao, and B. Si, "Road capacity at bus stops with mixed traffic flow in China," Transportation Research Record, no. 2111, pp. 18-23, 2009.

[18] J. A. Laval and C. F. Daganzo, "Lane-changing in traffic streams," Transportation Research Part B: Methodological, vol. 40, no. 3, pp. 251-264, 2006.

[19] R. Fernández, "Modelling public transport stops by microscopic simulation," Transportation Research Part C: Emerging Technologies, vol. 18, no. 6, pp. 856-868, 2010.

[20] M. Ghanim, F. Dion, and G. Abu-Lebdeh, "Integration of signal control and transit signal priority optimization in coordinated network using genetic algorithms and artificial neural networks," in Proceedings of the 88th Annual Meeting of the Transportation Research Board, Washington, DC, USA, January 2009.

[21] Q. He, K. L. Head, and J. Ding, "Heuristic algorithm for priority traffic signal control," Transportation Research Record, no. 2259, pp. 1-7, 2011.

[22] R. Li and X. Zhang, "Bus raid transit signal priority strategy based on schedule," in Proceedings of the 91st Annual Meeting of the Transportation Research Board, 2012.

[23] S. Yagar and B. Han, "A procedure for real-time signal control that considers transit interference and priority," Transportation Research Part B: Methodologica, vol. 28, no. 4, pp. 315-331, 1994.

[24] Z. R. Abdy and B. R. Hellinga, "Analytical method for estimating the impact of transit signal priority on vehicle delay," Journal of Transportation Engineering, vol. 137, no. 8, pp. 589-600, 2011.

[25] Y. Ji, B. Hu, J. Han, and D. Tang, "An improved algebraic method for transit signal priority scheme and its impact on traffic emission," Mathematical Problems in Engineering, vol. 2014, Article ID 412132, 11 pages, 2014.

[26] J. H. Holland, Adaptation in Artificial and Natural Systems, The University of Michigan Press, Ann Arbor, Mich, USA, 1975.

[27] Highway Capacity Manual, Transportation Research Board of the National Academies, Washington, Wash, USA, 2010.

[28] Transit Cooperative Research Program (TCRP), Report 100: Transit Capacity and Quality of Service Manual, Transportation Research Board of the National Academies, Washington, DC, USA, 2003. 


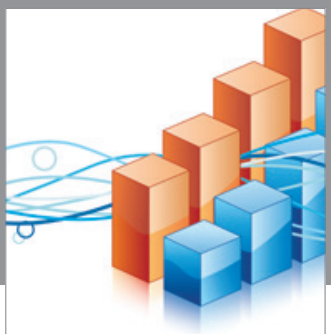

Advances in

Operations Research

vatem alat4

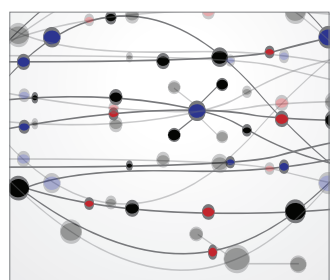

\section{The Scientific} World Journal
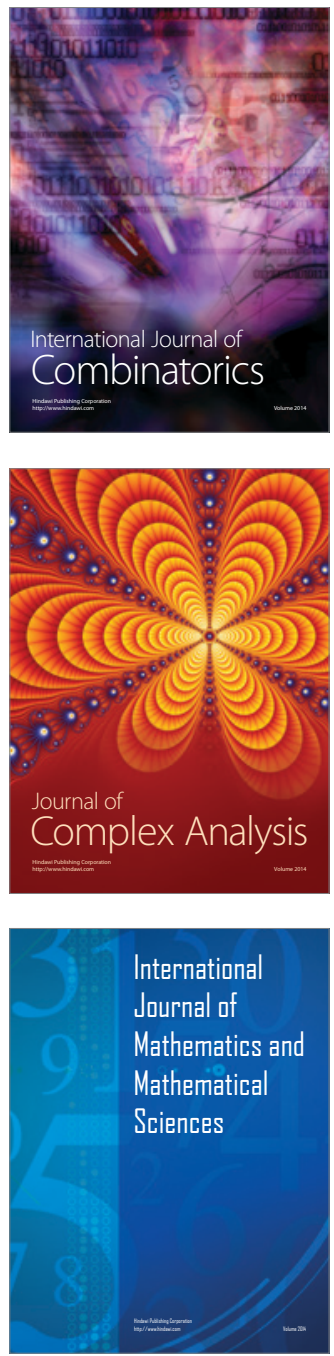
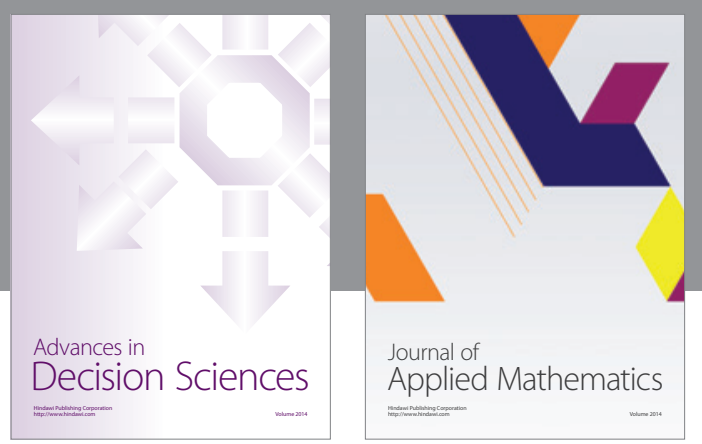

Algebra

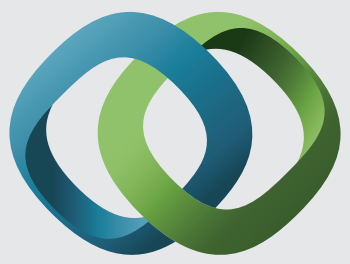

\section{Hindawi}

Submit your manuscripts at

http://www.hindawi.com
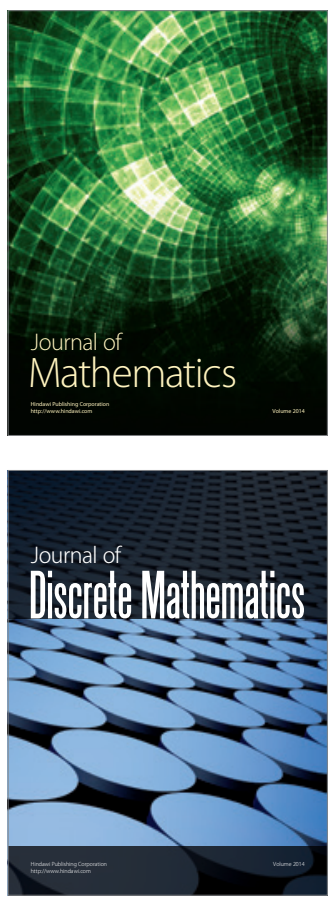

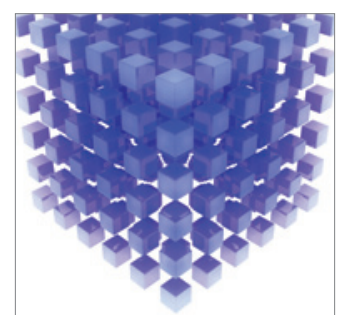

Mathematical Problems in Engineering
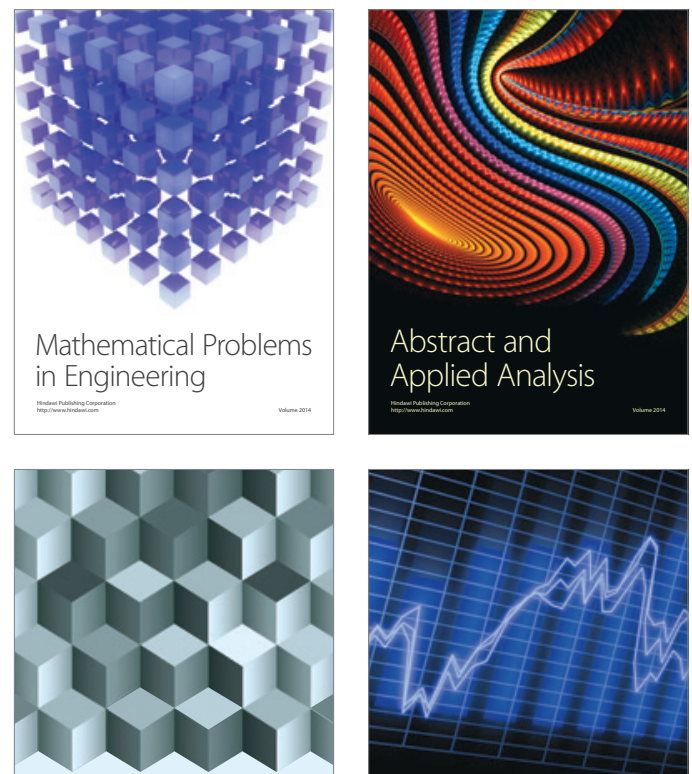

Journal of

Function Spaces

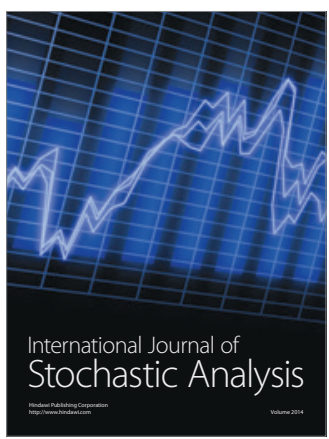

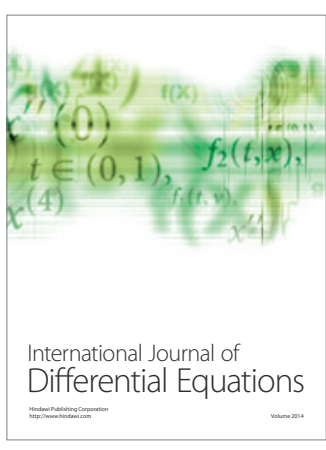
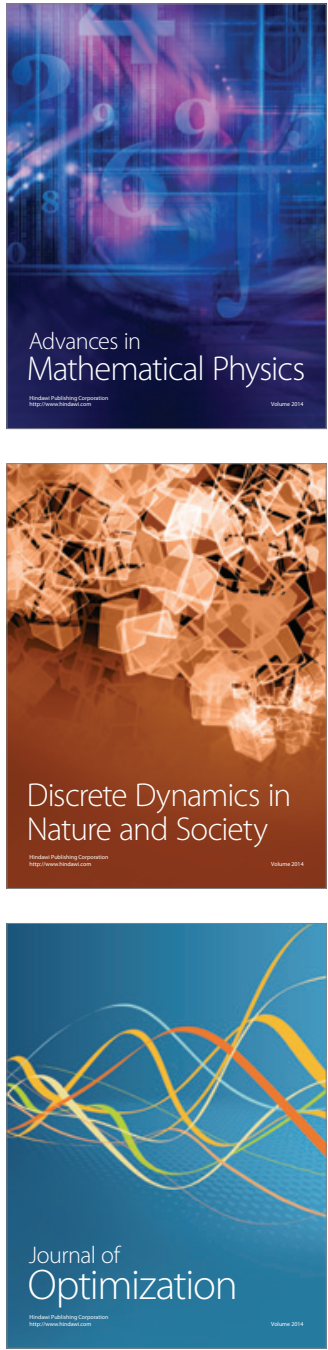